Quim. Nova, Vol. 28, No. 3, 462-471, 2005

\title{
MÉTODOS IMUNOQUÍMICOS PARA ANÁLISE DE CONTAMINANTES AMBIENTAIS: CONCEITOS, ESTADO DA ARTE E PERSPECTIVAS
}

\author{
Gilvanda Silva Nunes* \\ Departamento de Tecnologia Química, Universidade Federal do Maranhão, Av. Portugueses, s/n, 65080-040 São Luís - MA
}

Recebido em 6/2/04; aceito em 20/10/04; publicado na web em 28/2/05

\begin{abstract}
IMMUNOCHEMICAL METHODS FOR ANALYSIS OF ENVIRONMENTAL CONTAMINANTS: CONCEPTS, STATE OF THE ART AND PERPECTIVES. Immunoassay techniques provide simple, powerful and inexpensive methods for analysis of environmental contaminants. However, the acceptance of immunoassays is dependent on the clear demonstration of quality and validity compared to more traditional techniques. In this review, primarily, the understanding and the fundamentals of immunoassay methods are given in order to make good use of immunoassays, especially of EIA tests. Special attention is given to the concepts related to the enzymelinked immunosorbent assay (ELISA) formats, such as inhibition concentration at 50\% ( $\mathrm{IC}_{50}$ ), detection limit (LOD), cross-reactivity $(\mathrm{CR} \%)$. It is also explained why some immunoassays are quantitative methods whereas others can only be used as screening methods. A list of main commercial kits for detection of priority pollutants is given in order to help analysts. Others formats, such as flowinjection immunoassay analysis (FIIA), immunoassay chromatography and immunosensors are also cited.
\end{abstract}

Keywords: immunoassays; environmental contaminants; monitoring.

\section{INTRODUÇÃO}

A origem dos métodos imunológicos situa-se no final da década de 50, quando Yalow e Berson ${ }^{1}$ descreveram o primeiro ensaio imunológico para detectar insulina humana, o que lhes rendeu o Prêmio Nobel em 1977. A partir de então, as técnicas imunoquímicas foram desenvolvidas como métodos de análise de macromoléculas (enzimas, hormônios), e posteriormente para moléculas orgânicas pequenas (drogas, fármacos), tendo seu maior êxito no campo da química clínica ${ }^{2-4}$. Em meados da década de 70 , foi desenvolvido o primeiro ensaio biológico para pesticidas (aldrin e dieldrin $)^{5}$. A este ensaio, seguiram-se outros, também baseados na marcação radioativa, chamados ensaios radioimunológicos ("radioimmunoassay, RIA"). Os ensaios imunoenzimáticos ("enzyme immunoassay, EIA") surgiram na década de 60 para identificação e localização de antígenos em preparações histológicas ${ }^{2,6,7}$, tendo sido a sua utilidade reconhecida posteriormente em outros campos distintos ${ }^{8-13}$.

No início dos anos 80, começou-se a discutir as possibilidades que estes tipos de métodos analíticos podiam oferecer na detecção de contaminantes, tanto em amostras ambientais como de alimen$\operatorname{tos}^{12,14-16}$, o que fomentou a sua aplicação no campo da química ambiental. A partir desse momento, começou-se a utilizar a marcação enzimática, que proporcionava menores riscos e apresentava sensibilidade similar aos métodos convencionais de análise $\mathrm{e}^{12,15-19}$.

Inúmeras vantagens podem ser obtidas com a utilização dos métodos imunoquímicos e, paulatinamente, vão sendo disponibilizadas informações sobre diversos aspectos analíticos, tais como $i$ ) interpretação dos dados obtidos no desenvolvimento dos métodos; ii) estratégias utilizadas para a garantia da qualidade dos procedimentos operacionais; iii) análise dos dados e das informações lançadas em forma de relatórios técnicos, e iv) controle de qualidade para a melhoria da confiabilidade dos métodos, incluindo os ensaios para validação. Estes avanços são sentidos quando se verifica que algumas agências regulamentadoras, como a EPA ("US

*e-mail: vandasn@terra.com.br
Environmental protection Agency"), que antes eram reticentes quanto às técnicas bioanalíticos, já aceitam diversos imunoensaios como métodos de separação de amostras positivas ("screening methods"); as amostras serão então destinadas a análises posteriores empregando técnicas convencionais ${ }^{15}$. Tais agências já admitem, inclusive, a adoção de métodos já validados para fins quantitativos.

Os métodos imunoquímicos envolvem o uso de anticorpos, componentes-chave de todos os imunoensaios, sendo caracterizados por sítios de reconhecimento, presentes nas suas estruturas, que possibilitam interações altamente específicas com os antígenos. A geração de anticorpos para moléculas pequenas, como é o caso da maioria dos compostos de interesse ambiental, é extremamente difícil, porque moléculas de baixa massa molar não são hábeis na produção de respostas imunológicas. Esta é, certamente, a principal razão pela qual os métodos imunoquímicos foram primeiramente introduzidos para trabalhos no campo clínico ${ }^{2}$. Por outro lado, têm-se observado nas duas últimas décadas grandes progressos no desenvolvimento racional dos anticorpos para moléculas mais simples, inclusive voltados para análise de contaminantes em $\operatorname{alimentos}^{20}$.

Mesmo que as técnicas pareçam relativamente simples, torna-se necessário um prévio conhecimento de seus princípios básicos, bem como dos fundamentos dos diversos formatos de imunoensaios, para que se possa entender porque alguns imunoensaios são altamente seletivos e sensíveis para alguns compostos de interesse ambiental, enquanto que outros não o são, e porque alguns métodos imunoquímicos são quantitativos e outros só podem ser usados como métodos qualitativos (de separação ou 'alarme'). Este trabalho visa fornecer alguns elementos básicos para este entendimento.

\section{VANTAGENS E LIMITAÇÕES DOS ENSAIOS IMUNOLÓGICOS}

$\mathrm{O}$ apoio ao uso das metodologias imunoquímicas tem sido baseado em três pontos: $i$ ) alta sensibilidade alcançada por muitos imunoensaios, em alguns casos com limites de detecção abaixo de 
$0,1 \mu \mathrm{g} \mathrm{L^{-1 }}$ para análises de águas e de alimentos ${ }^{21}$, e até níveis de $1 \mu \mathrm{g} \mathrm{L}^{-1}$ em outros tipos de amostras como solos e matrizes biológi$\operatorname{cas}^{22}$; ii) elevada especificidade, que torna os imunoensaios capazes de detectar, com exatidão, um determinado contaminante, mesmo na presença de outro que possua estreita similaridade química com este, e iii) extrema simplicidade operacional, com possibilidade de se analisar, de uma só vez, inúmeras amostras. Em resumo, as principais qualidades atribuídas aos imunoensaios incluem sensibilidade, especificidade, rapidez, simplicidade e baixo custo.

No entanto, os ensaios imunológicos não são uma panacéia, uma vez que também apresentam inconvenientes. Diante de matrizes complexas, muitos deles servem apenas como técnicas de "screening", de modo a se estabelecer uma avaliação inicial da contaminação presente, devido ao desvio potencial para resultados falsamente positivos. Isto nos leva ao conceito de reatividade cruzada, que pode ser definida como a característica que apresentam alguns compostos estruturalmente relacionados com o composto principal, de modo a dar uma resposta positiva frente ao ensaio 9 . Além dessa característica - intrínseca do ensaio - podem-se também encontrar outras características próprias da matriz, que podem vir a interferir com a técnica, comumente denominadas efeito de matriz. Estas últimas características baseiam-se no fato de que os imunoensaios são formados por uma reação in vitro, sendo que as condições de tal reação, tais como $\mathrm{pH}$, força iônica, temperatura, tempo de reação, entre outras, afetarão de forma significativa a eficiência do ensaio.

A aceitação e implantação de metodologias baseadas em imunoensaios depende da clara demonstração de sua qualidade e validação, ao estabelecer-se a comparação entre os resultados obtidos com estas técnicas e aqueles provenientes dos métodos tradicionais. Dependendo do tipo de análise ambiental e do analito, os imunoensaios podem ser utilizados com sucesso como métodos de "screening", mas podem também fornecer dados quantitativos. Se for necessária a análise de um elevado número de amostras, entre as quais se esperam encontrar bem poucas contaminadas, é melhor realizar-se antes um ELISA ("enzyme-linked immunosorbent assay"), confirmando-se, posteriormente, as amostras positivas com métodos analíticos convencionais, como por ex. os espectrofotométricos ou cromatográficos ${ }^{9,14}$.

No Brasil, bem poucos grupos desenvolvem pesquisas com técnicas imunoquímicas que, entre as vantagens aqui discutidas, apresentam fatores econômico e ambiental positivos, por utilizarem soluções biológicas extremamente diluídas e por descartarem o uso de solventes orgânicos nos protocolos já propostos.

\section{DESENVOLVIMENTO DE UM IMUNOENSAIO}

O desenvolvimento de um imunoensaio para análise de qualquer composto compreende quatro fases bem diferenciadas:

- Seleção do composto de interesse: fase importante quando se tenciona realizar a análise de uma determinada classe de poluentes. Assim, a estrutura química desses compostos, sua estabilidade e os diferentes produtos de degradação, caso existam, são fatores que terão de ser considerados. A grande maioria dos pesticidas, por ex., dão origem a produtos de degradação, sob determinadas condições do meio $(\mathrm{pH}$, temperatura, etc.); estes, por sua vez, podem ou não interferir com o imunoensaio.

- Preparo dos reagentes: produção de anticorpos e compostos enzimáticos.

- Projeto do ensaio: seleção e aplicação das condições ótimas dos reagentes no ensaio.

- Otimização e avaliação do ensaio: definição e otimização dos parâmetros essenciais do ensaio, incluindo sensibilidade, exatidão, precisão, linearidade, reatividade cruzada, efeitos de matriz e avaliação da eficiência do ensaio quando aplicado à análise de amostras reais.

As três primeiras fases correspondem, em síntese, ao projeto do ensaio imunoquímico. A última está relacionada à caracterização do método e inclui também a validação deste, através de técnicas analíticas convencionais.

O objetivo principal do desenvolvimento de um imunoensaio é conseguir-se o máximo reconhecimento por parte do anticorpo em relação a um único composto, ou a uma classe particular de contaminantes. A maioria das proteínas e polipeptídios de elevado peso molecular são imunógenos naturais (capazes de produzir uma resposta imunológica) e podem, deste modo, ser injetados diretamente no animal sem nenhum tipo de modificação ${ }^{14,19}$. Na prática, um composto somente produzirá uma imunoresposta aceitável se sua molécula tiver um peso molecular a partir de 5000 daltons (Da) ${ }^{9}$. No desenvolvimento de um ensaio para contaminantes orgânicos, que normalmente são constituídos de moléculas muito pequenas (<1000 Da), devido ao fato de estes não produzirem uma imunoresposta, o procedimento para desenvolvimento do imunoensaio deve ser diferente. Neste caso, deve-se estabelecer uma ligação covalente entre a molécula do poluente (de baixo peso molecular) e uma molécula de maior peso molecular, geralmente uma proteína. Na terminologia dos estudos envolvendo imunologia, os compostos que possuem baixo peso molecular são denominados haptenos, e os conjugados do tipo hapteno-proteína são conhecidos como imunógenos ou imunoconjugados. Quando o conjugado hapteno-proteína (ou poluente-proteína) é injetado em um animal, este desencadeia uma resposta imunológica frente ao complexo, de forma que alguns anticorpos produzidos como conseqüência dessa resposta, dirigem-se contra as moléculas do poluente que estão unidas à proteína ${ }^{9,23}$.

Esta é uma fase laboriosa do trabalho e inclui três etapas: síntese dos haptenos, preparo dos imunógenos e a imunização em animais de laboratório (cobaias). Como já mencionado, a produção dos anticorpos é a chave para o sucesso no desenvolvimento de qualquer imunoensaio. A seguir, veremos alguns importantes conceitos imunológicos dentro de cada uma dessas etapas.

\section{Síntese dos haptenos}

Em muitas ocasiões, os compostos utilizados na obtenção dos anticorpos não apresentam nenhum grupo funcional para sua união covalente a uma molécula de maior tamanho. É por isso que se recorre à síntese dos haptenos.

Não existe um consenso geral sobre o procedimento ótimo para a produção de um hapteno, já que tal procedimento não obedece a regras perfeitamente definidas que garantam o êxito, mas sim existe apenas uma série de recomendações gerais a respeito ${ }^{19,24,25}$. Em teoria, o hapteno considerado adequado para um determinado analito deve imitar sua molécula quase à perfeição, tanto em estrutura, geometria, carga e propriedades hidrofóbicas, quanto em relação à sua capacidade de unir-se por ligações de pontes de hidrogênio ${ }^{25}$. Entretanto, algumas vezes, simples fragmentos característicos da molécula podem dar origem a bons anticorpos ${ }^{26}$. O problema reside no fato de que, para se poder acoplar covalentemente um determinado composto a uma proteína, é necessário que o primeiro disponha de grupos funcionais susceptíveis de serem utilizados para esse fim, tais como os grupamentos carboxila $(-\mathrm{COOH})$, amino $\left(-\mathrm{NH}_{2}\right)$, hidroxila $(-\mathrm{OH})$ ou sulfidrila (-SH). Infelizmente, uma grande parte dos compostos de interesse ambiental não possui tais grupos, o que torna necessária a sua introdução por modificação quí- 
mica do analito, ou por síntese de derivados que os contenham. É exatamente nesse momento que os haptenos são produzidos.

\section{Preparação dos imunógenos}

Uma vez sintetizado o hapteno, é necessário uni-lo covalentemente a uma proteína. Geralmente os haptenos são unidos às proteínas isoladas de espécies diferentes daquelas que se pretende imunizar. Para os animais habitualmente utilizados na produção de anticorpos (coelhos e camundongos), em geral são utilizadas as seguintes proteínas: as albuminas provenientes de soro bovino (BSA), de soro humano (HSA), de ovo de galinha (OVA); a tiroglobulina (TG), e a hemocianina $(\mathrm{KLH})^{26,27}$. A metodologia química empregada para o acoplamento do hapteno às proteínas depende do grupo funcional presente, existindo, assim, diversos procedimentos para cada tipo de hapteno $0^{24,28-30}$. Os métodos de conjugação usualmente empregados para a reação entre os grupamentos carboxila e amina, e a conseqüente formação do grupamento amida, são o método do anidrido misto ${ }^{28}$ e o método do éster ativo ${ }^{30}$.

Logo após a conjugação, torna-se necessária a realização de uma etapa de purificação dos conjugados hapteno-proteína, antes da imunização ${ }^{31}$. Também é muito importante verificar se a reação de conjugação teve êxito e, em seguida, caracterizar a estrutura do imunoconjugado antes da imunização, calculando-se o número de haptenos unidos à proteína. Normalmente, para se obter uma boa produção de anticorpos, são necessários entre 10 e 30 grupos haptênicos por cada $100 \mathrm{KDa}$ de proteína ${ }^{32}$, apesar de já terem sido obtidos resultados satisfatórios com relações mais altas ou mais baixas. Existem vários procedimentos - geralmente por espectrometria UV-vis - para se estimar quantitativamente o número de conjugados de hapteno unidos à proteína ${ }^{33-35}$, embora nos últimos anos tenham surgido outros métodos, como dessorção da matriz por meio de laser-espectrometria de massas (MALDI-MS) e a ionização "electrospray"-espectrometria de massas (ESI-MS) $)^{36-38}$.

\section{Produção dos anticorpos (imunização)}

Os imunógenos são utilizados para induzir a produção dos anticorpos no animal selecionado. Algumas revisões a respeito dos procedimentos de imunização podem ser encontradas ${ }^{19,39-42}$, mas em geral há ainda uma falta de guias desses procedimentos formais. Entretanto, é útil considerar-se os mecanismos implicados na imunoresposta e os fatores que a influenciam ${ }^{43,44}$. Estes fatores incluem o tipo de adjuvante ${ }^{45-47}$, a dose do imunógeno ${ }^{48-50}$, a escolha do animal, a rota de imunização ${ }^{51}$, o calendário de imunização e a natureza do imunógeno ${ }^{51,52}$.

A escolha da rota de imunização depende, essencialmente, do animal a ser imunizado. A maioria dos trabalhos envolve a utilização de camundongos, pois esses animais apresentam diversas vantagens sobre os demais, entre elas, as facilidades de obtenção, manutenção e manuseio, a vasta disponibilidade de animais de linhagem pura, destinados a diferentes estudos imunológicos, e a resposta imuno-humoral, cuja evolução é bastante semelhante à do homem $^{19,53}$. Contudo, dependendo do tipo de composto a ser testado, nem sempre o uso de animais de pequeno porte, como camundongos $^{54,55}$ e coelhos ${ }^{55,56}$, pode levar a uma imunoresposta com a sensibilidade esperada, o que obriga o pesquisador a mudar de animal. Deste modo, ovelhas, porcos, bois, cavalos e camelos têm sido também utilizados em investigações específicas ${ }^{53,57-60}$. A literatura registra ainda alguns trabalhos utilizando peixes ${ }^{61,62}$ e galinhas $^{63,64}$, mas estes apresentam baixa resposta, embora, no caso dos peixes, tenha sido verificada uma maior duração da imunoresposta.

\section{NATUREZA E ESTRUTURA DOS ANTICORPOS}

Os anticorpos pertencem a uma família de glucoproteínas relacionadas estruturalmente, chamadas imunoglobulinas (Ig), presentes no soro sanguíneo de todos os mamíferos. Tais proteínas são formadas naturalmente por indução da reação com os antígenos (substâncias estranhas). Na maioria dos animais superiores, cinco classes distintas de moléculas de imunoglobulinas são conhecidas: IgG, IgA, IgM, IgD e IgE, diferindo-se uma das outras em tamanho, carga, composição de aminoácidos e conteúdo de carboidratos $23,28,31$.

Em 1962, foi proposto um modelo básico para as imunoglobulinas: cadeias de proteínas com um número igual de cadeias pesadas (50-77 KDa) e de cadeias leves ( 25 KDa). As cadeias leves são comuns a todas as classes de imunoglobulinas, enquanto que as cadeias pesadas são estruturalmente diferentes de cada classe ou subclasse. A maiorias das imunoglobulinas pertence à classe das IgG e possui unicamente a unidade básica de quatro cadeias, consistindo de duas cadeias polipeptídicas leves idênticas, e outras duas pesadas, também idênticas. As cadeias pesadas estão unidas entre si por pontes de dissulfeto (-S-S-) e cada uma delas está unida, por sua vez, a uma cadeia leve, por pontes de dissulfeto e interações não-covalentes ${ }^{31,39,43}$. A unidade básica é simétrica, quer dizer, cada metade contém uma cadeia leve e outra pesada, resul-

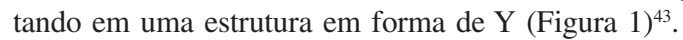

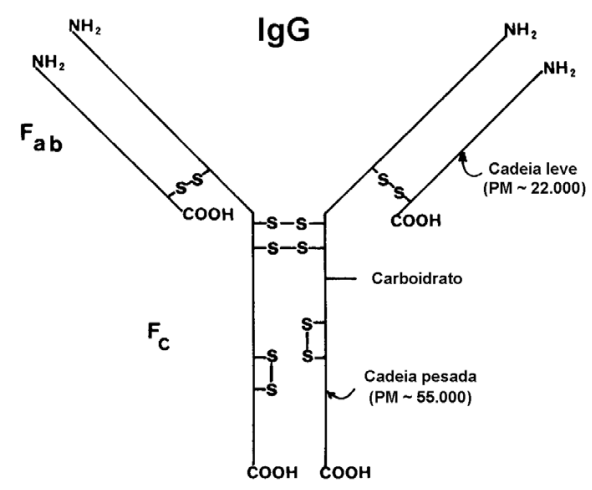

Figura 1. Estrutura básica de uma imunoglobulina do tipo G (anticorpo). Fab = fragmento que contém o sítio de ligação do antígeno (papaína), determinanate do anticorpo; a parte aminoterminal deste fragmento realiza $o$ reconhecimento e permite o acoplamento com o antígeno. $F c=$ fração constante da cadeia pesada, cuja função específica é a regulação da imunoresposta frente ao hospedeiro

A parte aminoterminal dos domínios das cadeias pesadas e leves do Fab são responsáveis pelo reconhecimento e pela união do antígeno, denominando-se domínio V (Fv, fração variável), que possui seqüências variáveis de aminoácidos ${ }^{40,43}$ e serve para acoplar o anticorpo de uma superfície complementar ao antígeno (interação 'chave-fechadura'). A alta afinidade que possui o anticorpo e o antígeno é determinada precisamente pela formação de pontes de hidrogênio, interações eletrostáticas, forças de Van der Waals e interações hidrofóbicas ${ }^{26}$. Os demais domínios (na metade carboxiterminal), denominados domínios C (constantes), são característicos de cada espécie e participam na regulação da imunoresposta, representando cerca de $90 \%$ da massa total do anticorpo. Esta divisão é que determina o papel bifuncional dos anticorpos: uma fração da molécula intervém na união específica com o antígeno, enquanto que a outra é responsável pela união dos tecidos e moléculas do hospedeiro, incluindo diversas células do sistema imunológico. A 
ativação de distintas funções biológicas depende das diferentes cadeias pesadas que possuem as imunoglobulinas, o que lhes confere uma classificação segundo a estrutura dessas cadeias ${ }^{52}$.

Os anticorpos gerados durante uma reação imunológica podem se unir a uma área específica da molécula do antígeno, chamada epítopo. Se o antígeno é muito grande, uma população heterogênea de diferentes anticorpos pode ser formada durante a imunização. Cada grupo de células B geneticamente idênticas ('clones') estimuladas produz seu próprio anticorpo característico, porém todos os anticorpos produzidos pelo mesmo clone são idênticos. Uma vez que não se podem separar os anticorpos de clones diferentes, o antisoro resultante é, por natureza, 'policlonal', isto é, os anticorpos são gerados por diferentes clones de células ${ }^{43,48,52}$.

Os anticorpos policlonais são os mais fáceis de se produzir; por outro lado, a biotecnologia possibilitou a produção de anticorpos 'monoclonais', a partir da fusão de células B únicas com células tumorais ${ }^{65,66}$, técnica desenvolvida por Köhler e Milstein em $1975^{67}$, e que lhes conferiu o Prêmio Nobel, em 1986. Se cada uma dessas fusões de células imortais é cultivada separadamente, podem ser obtidos os 'anticorpos monoclonais'. Além da uniformidade atribuída ao próprio processo de obtenção desses anticorpos, uma outra vantagem é que a mesma linha celular pode, virtualmente, produzir um número ilimitado de anticorpos com a mesma afinidade $\mathrm{e}$ especificidade, enquanto que o fornecimento de um antisoro policlonal está limitado ao do animal imunizado.

A tecnologia do DNA e a moderna engenharia de produção de anticorpos vêm suplementando e, em alguns casos, substituindo a tecnologia do hibridoma ${ }^{68}$. Anticorpos monoclonais recombinantes obtidos de vários animais, tais como galinhas, ovelhas ou lhamas, podem ser agora produzidos com certa facilidade. Recentemente, Lamari e seus colaboradores apresentaram uma breve revisão sobre esses métodos ${ }^{69}$. Basicamente, a produção de anticorpos a partir da tecnologia do DNA é realizada mediante procedimentos usados para ligar fragmentos de DNA heterólogos in vitro. Em condições apropriadas, a molécula do DNA recombinante pode penetrar na célula e replicar de forma autônoma (independente da replicação do cromossoma), ou mesmo após integrar em um cromossoma celular. Anticorpos anti-DNA podem ser assim obtidos pela imunização em animais, preferencialmente de grande porte. Para a imunização, cDNA específicos para a porção variável leve e pesada das imunoglobulinas são preparados, a partir dos respectivos hibridomas e, depois, clonados. A grande vantagem dessa técnica reside no fato de que os anticorpos são obtidos quase puros e apresentam elevada homologia. Contudo, a dificuldade operacional, a falta de disponibilidade de animais e a baixa reprodutibilidade na técnica são os grandes entraves para os biotecnologistas.

Existem inúmeros exemplos de anticorpos policlonais e monoclonais, desenvolvidos para aplicações em análises de contaminantes ambientais. Embora os antibióticos sejam considerados substâncias de interesse clínico, diversos formatos de imunoensaios têm sido desenvolvidos, utilizando-se diversos tipos de anticorpos, para análises de resíduos em amostras de leite, soro e água. Revisões sobre o desenvolvimento e a aplicação desses métodos foram recentemente apresentadas por Stead ${ }^{4}$ e Gil et al. ${ }^{66}$. Nas duas últimas décadas, diversos ensaios imunológicos foram desenvolvidos para análise de diferentes grupos de contaminantes ambientais, em especial pesticidas, apresentando baixos limites de detecção, tanto com anticorpos policlonais, quanto com monoclonais. No entanto, vários argumentos a favor ou contra a aplicação de um ou de outro têm sido discutidos na literatura ${ }^{27,70,71}$. Algumas vezes, um mesmo anticorpo pode ter aplicação em análises clínicas ou ambientais, dependendo da matriz; porém, de acordo com as interferências provocadas pelos demais componentes da amostra (efeito de matriz), a sensibilidade pode variar, para um mesmo tipo de ensaio imunoenzimático. Foi proposto, por isso, um protocolo para melhor seleção dos pares anticorpo-antígeno, destinados a certas aplicações clínicas ${ }^{72}$.

\section{PROJETO DO ENSAIO IMUNOENZIMÁTICO}

O projeto do imunoensaio constitui-se na escolha dos reativos e do protocolo a ser seguido, para se atingir o objetivo do ensaio: a quantificação, no menor tempo possível, da menor concentração possível do analito. Dentro dessa ótica, tem-se que selecionar o anticorpo (ou os anticorpos) com uma especificidade apropriada e uma afinidade característica. Para isto, deve-se ter em conta o princípio em que se baseia a interação entre o anticorpo e o antígeno. É importante também realizar a seleção dos marcadores utilizados para a quantificação, os suportes empregados e o método de separação (tipo de ensaio).

Em geral, os ensaios imunológicos constituem-se de métodos analíticos diretamente dependentes da união específica do anticorpo com seu analito. Esta interação é quantificável, graças à utilização de marcadores. Os diferentes tipos de marcadores incluem os radioisótopos $^{1,23}$, as enzimas ${ }^{6,7,23}$, a fluorescência ${ }^{73}$, a fosforescência $^{23,28}$, a quimioluminescência ${ }^{8,23,28}$ e a bioluminescência ${ }^{74}$. Os métodos mais usados até o presente momento utilizam enzimas e substratos colorimétricos, como aqueles empregados pela primeira vez por Miles e Hayes ${ }^{75}$, e posteriormente aplicados a ensaios imunológicos ${ }^{9}$. Os marcadores enzimáticos mais usados são a peroxidase ("horseradish peroxidase, HRP") e a fosfatase alcalina ("alkaline phosphatase, AP") ${ }^{76,77}$, que apresentam uma série de requisitos indispensáveis (elevada pureza, alta atividade específica, substrato estável, facilmente conjugável, etc. $)^{29}$.

Existe uma ampla variedade de suportes sólidos onde se pode acoplar o anticorpo (ou o antígeno, dependendo do EIA). Entretanto, podem ser divididos em dois grupos: partículas sólidas (em geral, partículas magnéticas de $1 \mu \mathrm{m}$ de diâmetro, nas quais os anticorpos se unem covalentemente), e superfícies sólidas (membranas, tubos e microplacas) $)^{78,79}$. Igualmente ampla é a variedade de procedimentos para se acoplar o anticorpo ou o antígeno à fase sólida $^{80,81}$. Entre todos os suportes sólidos existentes, as microplacas, conhecidas como placas de poliestireno irradiadas, são as mais populares, apesar de possuírem menor capacidade de fixação dos anticorpos ${ }^{82,83}$. Por outro lado, essas placas apresentam a vantagem de necessitarem uma quantidade muito pequena do marcador, além de possibilitarem o desenvolvimento de ensaios altamente sensíveis $^{81,83}$. Os fabricantes mais conhecidos das microplacas são as companhias Millipore, ImmunoSystem, Ensys e Quantix, enquanto que a Ohmicron Systems desenvolveu tecnologias altamente sofisticadas para a produção de partículas magnéticas.

\section{Tipos de ensaios imunoquímicos}

Os EIA podem ser de diversos tipos e formatos, em função dos quais a espécie do complexo anticorpo-antígeno conjugado é detectada $^{27,81}$. Assim, o número de possíveis configurações que um ensaio imunológico pode adotar é enorme, existindo uma confusa e extensa classificação e terminologia ${ }^{29}$. Apesar disto, pode-se dividir os diferentes tipos de EIA em dois grupos principais: ensaios imunoenzimáticos heterogêneos e ensaios imunoenzimáticos homogêneos. Os ensaios heterogêneos necessitam da separação, durante a análise, dos reativos unidos daqueles não-unidos. Os imunoensaios homogêneos são populares no campo clínico, enquanto que os heterogêneos possuem aplicação predominante na análise de matrizes ambientais ${ }^{81}$. 
Os EIA's heterogêneos também são conhecidos como ensaios imunoenzimáticos em suporte sólido, que incluem os ensaios nãocompetitivos e os ensaios competitivos. O primeiro tipo recebe a denominação de ensaio imunométrico 'sanduíche', devido ao fato de existirem dois tipos de anticorpos direcionados a diferentes epítopos do antígeno, formando um sanduíche do anticorpo unindo o antígeno no meio. O segundo, mostrado na Figura 2a, é denominado imunoensaio competitivo, uma vez que implica na competição entre o analito e o analito marcado, por um número limitado de sítios de união do anticorpo.

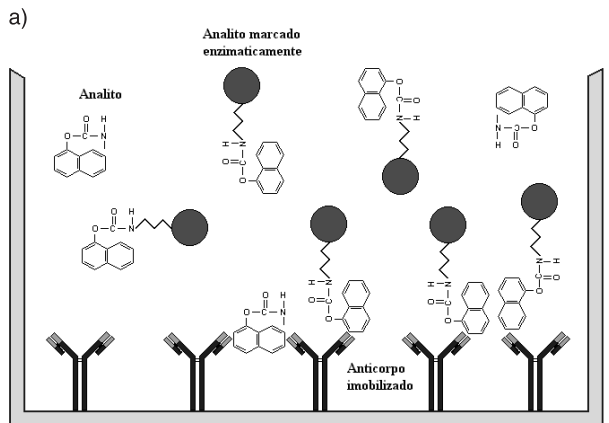

b)

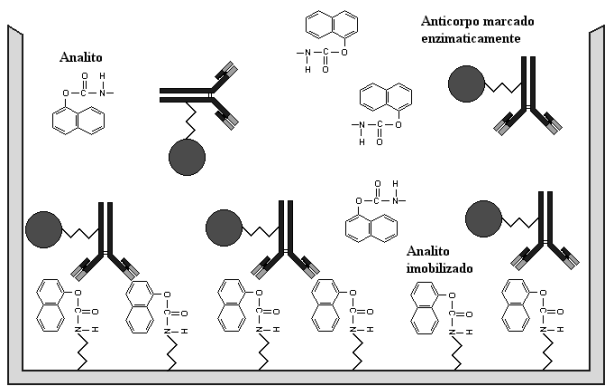

Figura 2. Imunoensaios competitivos desenvolvidos para o inseticida carbaril. a) ELISA competitivo com anticorpos imobilizados e posterior adição da solução contendo o analito e o analito marcado enzimaticamente; b) ELISA competitivo direto com antígenos imobilizados e posterior adição da solução contendo o analito e o anticorpo marcado enzimaticamente

Depois de uma etapa de lavagem, através da qual são separados os analitos dos analitos marcados que não se uniram ao anticorpo do meio, é medida a concentração dos analitos marcados unidos, graças ao processo de detecção da enzima. Este procedimento é viável para moléculas do analito de qualquer tamanho, mas requer a obtenção de um derivado de analito marcado que, em algumas ocasiões, não é fácil de se obter, ou seu processo de obtenção é muito caro. Para resolver este problema, pode-se imobilizar o antígeno em lugar do anticorpo (Figura 2b). Os dois ensaios apresentados como exemplos na Figura 2 foram desenvolvidos para análise do inseticida carbaril. Posteriormente, observou-se que o ensaio do tipo sanduíche, desenvolvido por Montoya et al. ${ }^{84}$, era mais eficiente na determinação desse contaminante, cuja molécula é extremamente pequena. Este método foi, então, adaptado para análise direta de amostras vegetais $^{85,86}$ e ambientais ${ }^{87}$. A diferença do formato de ELISA tipo sanduíche é que neste ensaio competitivo o sinal gerado é inversamente proporcional à concentração do analito.

\section{Processamento do sinal analítico}

Em um ensaio ELISA, contendo uma quantidade conhecida de anticorpos unidos a um suporte sólido, bem como uma concentração fixa de conjugados enzimáticos, a determinação fotométrica da atividade enzimática por absorção está relacionada à concentração do analito via uma curva concentração-resposta (ou curva doseresposta), representada na Figura 3. Este tipo de curva é construída com concentrações de antígeno resultando em uma forma sigmóide, com uma região central linear. Quando a concentração do analito é muito baixa, o equilíbrio está a favor de uma alta concentração do conjugado enzimático unido aos anticorpos, e sua absorbância correspondente será a mais alta. A faixa de trabalho dessa curva de calibração está delimitada pelos limites superior e inferior. Dentro dessa faixa, a variação de absorbância está relacionada com a concentração do analito. Em concentrações mais elevadas (limite superior), o ensaio está saturado e um incremento na concentração de analito não produz nenhum efeito. A faixa de trabalho desse tipo de curva é uma característica importante, e fornece uma pri-

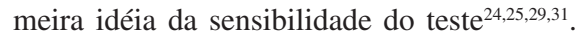

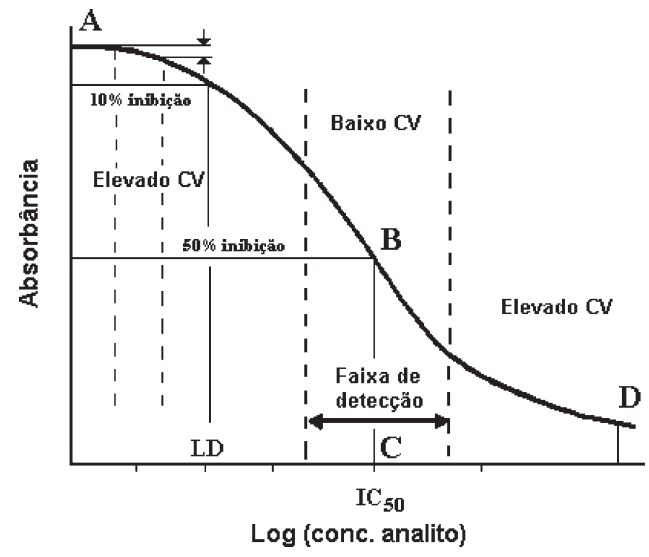

Figura 3. Curva de calibração representativa de ensaios imunológicos competitivos, com indicação de seus parâmetros característicos, após seu ajuste com uma equação logarítmica de quatro parâmetros. $C V=$ coeficiente de variação. $L D=$ limite de detecção

A forma mais comum de representar essa curva é com a variação da absorbância, A, utilizando-se uma abscissa logaritmica para a concentração do analito. No entanto, para se realizar uma comparação direta de várias curvas-padrão, os dados de absorbância podem ser normalizados entre $100 \%$ (absorbância medida em concentração zero, $A_{0}$ ) e $0 \%$ (absorbância medida em concentração em excesso, $\left.\mathrm{A}_{\text {excesso }}\right)$. A transformação é realizada de acordo com os valores de $\% \mathrm{~B} / \mathrm{B}_{0}$ :

$\% \mathrm{~B} / \mathrm{B}_{0}=\left(\mathrm{A}-\mathrm{A}_{\text {excesso }}\right) /\left(\mathrm{A}_{0}-\mathrm{A}_{\text {excesso }}\right) \times 100$

onde A é a absorbância da amostra ou padrão. É conveniente representar as curvas-padrão obtidas com os valores da absorbância ou da $\% \mathrm{~B} / \mathrm{B}_{0}$, em função do logaritmo da concentração do analito, uma vez que é mais fácil se incorporarem os dados originais sobre o gráfico. A fim de se obter melhor linearidade, diversas transformações matemáticas foram propostas ${ }^{88,89}$, mas o tipo de transformação que melhor se aproxima a essa classe de curvas é a dos quatro parâmetros logaritmicos ${ }^{89}$, obtida mediante regressão nãolinear, definida pela seguinte equação:

$y=\left[(\mathrm{A}-\mathrm{D}) /\left[1+(x / \mathrm{C})^{\mathrm{B}}\right]\right]+\mathrm{D}$

onde $y$ é a absorbância; $x$, a concentração do analito; A, a assíntota máxima (correspondente à absorbância na ausência do analito, $\mathrm{A}_{0}$ ); 
$\mathrm{B}$, a inclinação da curva no ponto de inflexão; $\mathrm{C}$, o valor de $x$ no ponto de inflexão (correspondente à concentração do analito que produz uma redução de $50 \%$ de $\mathrm{A}_{0}$ ), e D é a assíntota mínima (sinal de fundo, $\mathrm{A}_{\text {excesso }}$ ) (Figura 3).

Na curva dose-resposta podem-se também observar outros parâmetros relacionados com a sensibilidade do ensaio imunológico. A sensibilidade pode ser expressa pelo limite de detecção (LD), que é considerado como sendo a mais baixa concentração do analito que produz um sinal que pode ser significativamente distinguido da concentração zero, com certo grau de confiança. Embora não exista uma forma padrão de definir esse limite, há um consenso geral em escolher a concentração do analito que iniba $10 \%$ da união do anticorpo com o conjugado enzimático; este seria então o valor de $90 \%$ de B/ $\mathrm{B}_{0}$. Outra forma de descrever esse limite seria considerá-lo como sendo duas ou três vezes o desvio padrão da média da medida do sinal obtido quando a concentração do analito é zero ${ }^{82,90}$.

Na porção não-linear da curva, a variância não é uniforme e os erros experimentais aumentam à medida que se afasta da parte linear da curva (central). Assim sendo, a precisão do teste poderia ser determinada em função do coeficiente de variação. A melhor precisão é encontrada para valores de concentração mais próximos daquela concentração onde $50 \%$ das moléculas do traçador enzimático se deslocaram do anticorpo na presença de certa concentração do analito, isto é, no ponto $50 \% \mathrm{~B} / \mathrm{B}_{0}$. Este parâmetro, denominado $I C_{50}$ ("Inhibition Concentration at 50\%"), é normalmente utilizado para expressar a sensibilidade do imunoensaio ${ }^{40,89,91}$.

$\mathrm{O}$ valor de $\mathrm{IC}_{50}$ é igualmente útil quando se deseja comparar diferentes curvas, tanto do próprio analito, quanto de diferentes compostos, comumente denominados "cross-reactants", que podem dar uma resposta positiva ante o ensaio. Isto implica dizer que este parâmetro poderá nos dar uma idéia da reatividade cruzada (“cross-reactivity, CR") de um composto que não seja o analito ${ }^{40,48,50,88}$, segundo a seguinte equação:

$\mathrm{CR}(\%)=\left(\mathrm{IC}_{50}\right.$ do analito $/ \mathrm{IC}_{50}$ do composto $) \times 100$

Em um estudo recente ${ }^{92}$, um "kit" baseado em um imunoensaio competitivo do tipo ELISA para determinação de compostos aromáticos policíclicos foi utilizado, e as reatividades cruzadas foram determinadas para 16 compostos, incluindo antraceno e seus derivados, fenantreno, fluoreno, dibenzofurano, naftaleno e seus derivados, entre outros. O "kit" foi aplicado à análise de solos, apresentando boa sensibilidade e baixos valores de CR, tomando-se o fenantreno como substância referência. Estudo similar foi desenvolvido anteriormente $^{93}$, tendo sido obtidas as RC para 19 compostos.

\section{AVANÇOS E PERSPECTIVAS}

Os avanços mais recentes na área dos métodos imunoquímicos incluem o desenvolvimento de novos formatos de ensaios ${ }^{10,63,81}$, de ensaios multiresiduais ${ }^{68,81}$, de imunoensaios hifenados com FIA ("Flow Injection Analysis") ${ }^{10}$, além do surgimento de diversos métodos envolvendo cromatografia por imunoafinidade ${ }^{10,94}$.

Avanços na biotecnologia têm permitido também a produção de anticorpos policlonais, monoclonais e até recombinantes ${ }^{19,81}$ altamente seletivos para diferentes tipos de contaminantes ambientais, incluindo alguns dos pesticidas de última geração, dioxinas e microcistinas (Tabelas 1 e 2). Revisões sobre os métodos utilizando biomarcadores e imunoensaios para análise de dioxinas foram recentemente apresentadas ${ }^{139-141}$. Imunoensaios para bifenilas

Tabela 1. Anticorpos policlonais desenvolvidos para análises de contaminantes ambientais por ELISA

\begin{tabular}{|c|c|c|}
\hline Haptenos & Sensibilidade do imunoensaio & Ref. \\
\hline \multicolumn{3}{|l|}{ - Herbicidas } \\
\hline 2,4-D & $100 \mathrm{ppb}^{*}$ & 95 \\
\hline atrazina & 100 ppb (cobaia; coelho; amostra de água) & 96, 97 \\
\hline & 0,3 ppb (cobaia; ovelha; amostra de água) & \\
\hline dicamba & $10 \mathrm{ppb}$ & 98 \\
\hline glifosato & 1 ppm (amostra de solo) & 99 \\
\hline metalaclor, alaclor & $0,06-0,4 \mathrm{ppb}$ & 100 \\
\hline paraquat & $0,1 \mathrm{ppb}$ (amostra de solo) & 101 \\
\hline picloram & $10 \mathrm{ppb}$ & 102 \\
\hline \multicolumn{3}{|l|}{ - Inseticidas } \\
\hline etofenproxi & 1 ppb (amostra de água) & 103 \\
\hline fenitrotion & $0,3 \mathrm{ppb}$ & 104 \\
\hline fenoxicarb & $0,5 \mathrm{ppb}$ & 105 \\
\hline organofosforados & 0,1 ppb (cobaia; coelho) & 106,107 \\
\hline & 0,1 nM (cobaia; galinha) & \\
\hline esfenvalerato & $3 \mathrm{ppb}$ & 108 \\
\hline \multicolumn{3}{|l|}{ - Fungicidas } \\
\hline tiabendazol & 9 ppb & 109 \\
\hline tiram & $30 \mathrm{ppb}$ & 110 \\
\hline \multicolumn{3}{|l|}{ - Antibióticos } \\
\hline espectinomicina & $2 \mathrm{ppb}$ & 111 \\
\hline \multicolumn{3}{|l|}{ - Outros } \\
\hline clorofenóis & $0,7-1 \mathrm{ppb}$ & 112 \\
\hline naftaleno & $1-2 \mathrm{ppb}$ & 113 \\
\hline bisfenol A & 2,5 $\mu \mathrm{M}$ (amostra de água) & 114 \\
\hline \multirow[t]{4}{*}{ hidrocarbonetos poliaromáticos } & $0,9 \mathrm{ppb}$ & $93,114,115,116$ \\
\hline & $0,5-4 \mathrm{ppb}$ & \\
\hline & 200 ppb a 5 ppm (amostra de solo) & \\
\hline & $400 \mathrm{ppb}$ (óleo de transformador) & \\
\hline bifenilas policloradas & $0,6-12 \mathrm{ppb}$ & 117 \\
\hline
\end{tabular}

Quando não indicada a fonte do anticorpo, entende-se que este foi produzido em coelhos. 
Tabela 2. Anticorpos monoclonais desenvolvidos para análises de contaminantes ambientais por ELISA

\begin{tabular}{|c|c|c|}
\hline Haptenos & Sensibilidade do imunoensaio & Ref. \\
\hline \multicolumn{3}{|l|}{ - Herbicidas } \\
\hline 2,4-D & $0,1 \mathrm{ppb}$ & 118 \\
\hline atrazina & $0,1 \mathrm{ppb}$ & 119,120 \\
\hline & $1 \mathrm{nM}$ & \\
\hline iIsoproturon & $20 \mathrm{ppb}$ & 121 \\
\hline paraquat & $1 \mathrm{ng}$ & 122 \\
\hline metalaclor, alaclor & 0,06-0,4 ppb (amostra de água) & 100 \\
\hline paraquat & $0,1 \mathrm{ppb}$ & 101 \\
\hline picloram & $10 \mathrm{ppb}$ & 102 \\
\hline terbutilazina & $\mathrm{IC}_{50}=0,13 \mathrm{ppb}$ (amostra de água) & 123 \\
\hline \multicolumn{3}{|l|}{ - Inseticidas } \\
\hline azinfos metílico & $\mathrm{IC}_{50}=$ abaixo de $\mathrm{nM}$ & 124 \\
\hline propoxur & $\mathrm{IC}_{50}=6,5 \mathrm{nM}$ & 125 \\
\hline carbaril & $0,1 \mathrm{ppb}$ & 126 \\
\hline carbofuran & $\mathrm{IC}_{50}=0,74 \mathrm{ppb}$ & 125,127 \\
\hline organofosforados & $1 \mathrm{ppb}$ & 106 \\
\hline \multicolumn{3}{|l|}{ - Fungicidas } \\
\hline tiabendazol & 0,05 ppb (amostra de água) & 127 \\
\hline \multicolumn{3}{|l|}{ - Antibióticos } \\
\hline gentamicina & $0,5-0,7 \mathrm{ppb}$ (amostra de leite e soro) & 128,129 \\
\hline estreptomicina & $0,8-10 \mathrm{ppb}$ & $128,130,131,132$ \\
\hline neomicina & $0,7-3,6 \mathrm{ppb}$ & 128 \\
\hline \multicolumn{3}{|l|}{ - Outros } \\
\hline dinitrofenol & $K_{\mathrm{d}}=1 \mathrm{mM}$ & 133 \\
\hline \multirow[t]{4}{*}{ hidrocarbonetos poliaromáticos } & $2 \mathrm{nM}$ & $93,116,134,135$ \\
\hline & $0,1 \mathrm{ppb}$ (amostra de água e sedimentos) & \\
\hline & 200 ppb a 5 ppm (óleo de transformador) & \\
\hline & 2,21 a $1500 \mathrm{ppb}$ & \\
\hline dioxinas & 20 ppb (amostra de água) & 136 \\
\hline dioxinas e furanos & $\mathrm{IC}_{50}=4-5 \mathrm{ppb}($ amostra de solo $)$ & 137 \\
\hline bifenilas policloradas & 2,6 pmol (amostra de alimentos e água) & 138 \\
\hline
\end{tabular}

Quando a sensibilidade não é apresentada como $\mathrm{IC}_{50}$, trata-se do limite de detecção. Quando não especificado o tipo de amostra, trata-se apenas do desenvolvimento e caracterização do imunoensaio.

policloradas, dioxinas e dibenzofuranos policlorados também foram revisados ${ }^{142}$.

As microcistinas são consideradas poluentes naturais em ambientes aquáticos, podendo também caracterizar a poluição de origem antropogênica. Em 1985, na Austrália, 25 pessoas foram contaminadas após consumirem água contaminada com cilindrospermopsina, uma toxina produzida pela cianobactéria Cylindrospermopsis raciboskii ${ }^{143}$. Em 1996, a morte de 50 pacientes em um hospital no estado de Pernambuco foi atribuída à intoxicação por essas toxinas provenientes de cianobactérias contidas na água utilizada para a hemodiálise $^{144}$. O uso de ensaios imunoenzimáticos para a detecção de microcistinas já é uma realidade, e os métodos baseiam-se na inibição competitiva da enzima fosfatase alcalina ${ }^{145-151}$. Também já se podem ser encontrados no mercado "kits" para análise rápida, não só desses poluentes, como de muitos outros; tais sistemas vêm sendo amplamente utilizados em estudos e monitoramentos ambientais.

Desde a conferência sobre validação de métodos bioanalíticos, que ocorreu na cidade de Crystal (EUA), e que foi organizada pelas agências reguladoras americana ("Food and Drug Administration, FDA") e canadense ("Health Protection Branch, HPB"), além de inúmeras outras organizações científicas, incluindo a IUPAC, diversos procedimentos e regras para desenvolvimento, validação e aplicação dos métodos imunoquímicos têm surgido, estando voltados principalmente para a indústria farmacêutica ${ }^{152,153}$. Contudo, esses protocolos têm servido de base para trabalhos com amostras ambientais.
Os "kits" de imunoensaios também têm-se constituído em uma poderosa ferramenta para a biomonitorização de poluentes no organismo humano, principalmente no campo da epidemiologia ambiental e ocupacional ${ }^{154-161}$. A Tabela 3 apresenta alguns exemplos desses kits de imunoensaios para detecção de poluentes considerados prioritários para (bio)monitorização e monitorização ambiental. Uma grande atenção tem sido dada à detecção/ quantificação de resíduos de pesticidas, principalmente os compostos de última geração, cuja polaridade varia de mediana a alta, e que têm sido freqüientemente encontrados nos ambientes aquáticos, na biota e também nos alimentos ${ }^{162-164}$. A Figura 4 apresenta um esquema de análise rápida desses contaminates, utilizando um kit do tipo placa. Na maioria dos casos, em menos de $1 \mathrm{~h}$ de análise pode-se ter uma resposta. Infelizmente, em alguns formatos, problemas com reatividade cruzada e falta de reprodutibilidade dificultam o uso desses kits como métodos confiáveis de análise. Em determinados produtos comerciais, observa-se também uma validade menor que a indicada pelo fabricante, para certos imunoreagentes que acompanham o kit, mesmo obedecendo-se todos os cuidados de armazenamento e transporte. Isto, efetivamente, pode alterar os resultados dos testes e fornecer resultados falsamente positivos ou negativos.

Imunossensores amperométricos automatizados e, na maioria dos casos, operando em FIA, têm sido desenvolvidos para análise de poluentes de baixo peso molecular ${ }^{165,166}$, e uma nova categoria 
Tabela 3. Alguns kits de imunoquímicos comerciais para (bio)monitorização de poluentes prioritários

\begin{tabular}{|c|c|}
\hline Composto detectado & Fabricante \\
\hline \multicolumn{2}{|l|}{ - Pesticidas } \\
\hline acetoclor & Millipore (P) \\
\hline alaclor & $\begin{array}{l}\text { Baker }(\mathrm{T}) \text {, Millipore }(\mathrm{P}, \mathrm{T}) \text {, } \\
\text { Quantix }(\mathrm{P})\end{array}$ \\
\hline aldicarb & $\begin{array}{l}\text { Baker }(\mathrm{T}), \text { Millipore }(\mathrm{P}, \mathrm{T}) \text {, } \\
\text { EnviroLogix }(\mathrm{P})\end{array}$ \\
\hline atrazina (triazinas) & $\begin{array}{l}\text { Baker }(\mathrm{T}) \text {, Millipore }(\mathrm{P}, \mathrm{T}) \\
\text { R-Biopharm }(\mathrm{P}) \text {, EnviroLogix }(\mathrm{P})\end{array}$ \\
\hline benomyl (MBC) & Quantix (P) \\
\hline captan & Baker $(\mathrm{T})$ \\
\hline carbaryl & Baker $(\mathrm{T})$ \\
\hline carbendazim & Baker $(\mathrm{T})$ \\
\hline carbendazim/benomil & Millipore (T), EnviroLogix (P) \\
\hline carbendazim/MBC & Millipore $(\mathrm{P})$ \\
\hline clordane & Millipore (T) \\
\hline clorpirifos & Baker $(\mathrm{T})$, EnviroLogix $(\mathrm{P})$ \\
\hline $2,4-\mathrm{D}$ & Baker (T), Millipore (P, T) \\
\hline DDT & Millipore $(\mathrm{P})$, EnviroLogix $(\mathrm{P})$ \\
\hline fenitrotion & Millipore $(\mathrm{P}, \mathrm{T})$ \\
\hline glifosato & EnviroLogix $(\mathrm{T})$ \\
\hline isoproturon & Millipore $(\mathrm{P})$ \\
\hline metolaclor & Baker (P), Quantix (P) \\
\hline paraquat & $\begin{array}{l}\text { Baker }(\mathrm{T}) \text {, Millipore }(\mathrm{P}) \text {, } \\
\text { EnviroLogix }(\mathrm{P})\end{array}$ \\
\hline paration/paration metílico & Millipore (P), EnviroLogix (P) \\
\hline trifluralina & Quantix (P) \\
\hline triclopir & Baker $(\mathrm{T})$ \\
\hline herbicidas urea & Millipore (P) \\
\hline piretróides sintéticos & EnviroLogix $(\mathrm{P})$ \\
\hline - BTEX & $\begin{array}{l}\text { Baker }(T) \text {, Millipore }(T) \text {, Quantix } \\
(\mathrm{P}) \text {, Drager }(\mathrm{T})\end{array}$ \\
\hline - pentaclorofenol & $\begin{array}{l}\text { Baker }(\mathrm{T}) \text {, Drager }(\mathrm{T}) \text {, Millipore } \\
(\mathrm{T})\end{array}$ \\
\hline - bifenilas policloradas & $\begin{array}{l}\text { Baker }(\mathrm{T}) \text {, Drager }(\mathrm{T}) \text {, Millipore } \\
(\mathrm{T})\end{array}$ \\
\hline $\begin{array}{c}\text { - hidrocarbonetos } \\
\text { poliaromáticos }\end{array}$ & $\begin{array}{l}\text { Baker }(\mathrm{T}) \text {, Drager }(\mathrm{T}) \text {, Millipore } \\
(\mathrm{T}) \text {, Quantix }(\mathrm{P}), \text { Strategic } \\
\text { Diagnostics Inc. }(\mathrm{T}), \\
\text { EnviroGard }(\mathrm{T}), \text { SDI }(\mathrm{T}), \\
\text { Ohmicron }(\mathrm{T})\end{array}$ \\
\hline - TNT & $\begin{array}{l}\text { Millipore }(\mathrm{P}, \mathrm{T}) \text {, R-Biopharm }(\mathrm{P}) \text {, } \\
\text { SDI }(\mathrm{T}) \text {, Ohmicron }(\mathrm{T}) \text {, BioGenes } \\
(\mathrm{P}) \text {, Immunolab (P), } \\
\text { R-Biopharm }(\mathrm{P})\end{array}$ \\
\hline - acetanilidas & EnviroLogix $(\mathrm{P})$ \\
\hline - dioxinas & $\begin{array}{l}\text { EnviroGard }(\mathrm{P}), \text { SDI }(\mathrm{P}) \text {, } \\
\text { Millipore }(\mathrm{P}), \text { BioScan Screening } \\
\text { Systems }(\mathrm{T}), \\
\text { CAPE Technologies }(\mathrm{T})\end{array}$ \\
\hline • mercúrio & BioNebraska $(\mathrm{T})$ \\
\hline - microcistinas & EnviroLogix $(\mathrm{P})$, Abraxis LLC $(\mathrm{P})$ \\
\hline
\end{tabular}

$\mathrm{P}=$ kit em placa; $\mathrm{T}=$ kit em tubo

de sistemas analíticos foi descrita pela primeira vez em 1992, dando origem aos sistemas de imunoanálises por injeção em fluxo ("flow-injection immunoanalysis systems", FIIA) ${ }^{10}$. Em geral, os biossensores dispensam o tratamento da amostra, principalmente se esta for líquida ou pastosa, sendo ainda muito mais rápidos e

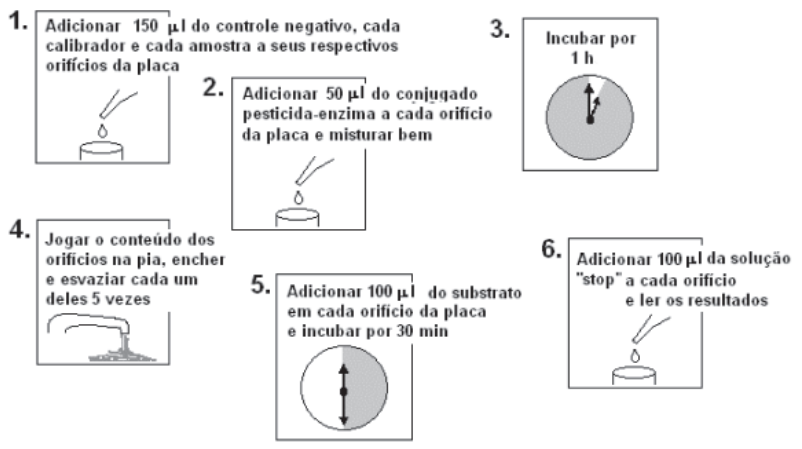

Figura 4. Análise rápida de um poluente utilizando um kit de imunoensaio do tipo placa

sensíveis que os métodos convencionais. Anticorpos podem ser utilizados como reagentes altamente seletivos em biossensores amperométricos ou óticos. Contudo, é importante mencionar que, por definição, um método analítico baseado em um imunossensor não pode ser considerado um imunoensaio, porque no caso dos biossensores existe, inexoravelmente, a presença de um transdutor. São verificadas ainda muitas distorções conceituais nesse campo da análise química.

O desenvolvimento de imunossensores tem sido limitado pelo fato de que as interações anticorpo-antígeno não são prontamente reversíveis ${ }^{66}$, e o uso de agentes que promovem a dissociação dessas ligações não tem resultado, na maioria dos casos, em procedimentos reprodutíveis. Também, o uso de sistemas em fluxo acoplados a imunossensores não tem se mostrado uma tarefa fácil, e as pesquisas para o melhoramento dos sistemas em FIIA encontram, atualmente, seu foco nas seguintes vertentes: $i$ ) desenvolvimento de novos imunoreagentes (anticorpos mais específicos, para construção de sistemas multianalíticos); ii) estudos de novos formatos de EIA's, de modo a minimizar os inconvenientes relacionados com instabilidades dos reagentes e regeneração na imunosuperfície; iii) aplicação de metodologias já estabelecidas, como por ex., o uso de fibras óticas, para o desenvolvimento de sistemas miniaturizados e portáteis, e iv) desenvolvimento de imunosenssores capazes de determinar, simultaneamente, mais de um analito, através do uso de vários anticorpos e marcadores enzimáticos ao mesmo tempo ${ }^{167}$. Tais tecnologias poderão, no futuro, vir a ser a base para programas internacionais destinados ao controle "online" de poluição ambiental $^{168}$.

Um dos atuais grandes desafios no campo do desenvolvimento de imunoensaios é o estabelecimento de formatos que não empreguem marcadores. Como já mencionado, os EIA's mais atuais utilizam compostos fluorogênicos ( $\mathrm{I}^{125}$, isótopo radiativo do iodo), quimiluminogênicos (p. ex., compostos fluorescentes como o isotiocianato de fluoresceína e a rodamina) e, principalmente, enzimas como marcadores. Os marcadores radiativos possuem vida útil extremamente curta e os fluorescentes são altamente sensíveis a pequenas mudanças de $\mathrm{pH}$ e temperatura. Além disso, se a amostra contiver substâncias que emitam naturalmente radiação no mesmo comprimento de onda que estes últimos marcadores, a mensuração da fluorescência pode ser superestimada. $\mathrm{O}$ uso de enzimas como marcadores ainda é a melhor alternativa, porém algumas enzimas são extremamente caras, o que torna o método economicamente inviável. A eliminação do uso de marcadores tem sido possível, com sucesso, através do uso da imunocromatografia ${ }^{169}$, mas a hifenação desta técnica com FIA, sem dúvida, possibilitará resultados mais rápidos e reprodutíveis ${ }^{170}$. 


\section{AGRADECIMENTOS}

A autora agradece o apoio do $\mathrm{CNPq}$ pelo suporte financeiro.

\section{REFERÊNCIAS}

1. Yalow, R. S.; Berson, S. A.; Nature 1959, 184, 1648.

2. Thienpont, L. M.; Van Uutfanghe, K.; Leenheer, A. P.; Clin. Chim. Acta 2002, 323, 73 .

3. Lamari, F.; Anastassiou, E. D.; Dimitracopoulos, G.; Karamanos, N. K.; J. Pharm. Biomed. Anal. 2000, 23, 939.

4. Stead, D. A.; J. Chromoatogr., B: Biomed. Sci. Appl. 2000, 747, 69.

5. Langone, J. J.; Nvunakis, H.; Res. Commun. Chem. Path. Pharm. 1975, $10,163$.

6. Nakane, P. K.; Pierce, G. B.; J. Histochem. Cytochem. 1966, 14, 929.

7. Nakane, P. K.; Pierce, G. B.; J. Cell Biol. 1967, 33, 307.

8. Tijssen, P.; Kurstak, E. Em Viral immunodiagnosis; Kurstak, E.; Morisset, R., eds.; Academic Press Ltd.: New York. 1974, p. 125.

9. Ercegovich, C. D. Em Analysis of Pesticide Residues: Immunological Techniques; Nelson, J. O.; Karu, A. E.; Wong, R. B., eds.; American Chemical Society: Washington, DC, 1991, p. 162.

10. Gonzalez-Martínez, M. A.; Puchades, R.; Maquieira, A.; Trends Anal. Chem. 1999, 18, 204.

11. Knopp, D.; Anal. Chim. Acta 1995, 311, 383

12. Nistor, C.; Emnéus, J.; Waste Manag. 1999, 19, 147.

13. Findlay, J. W. A.; Smith, W. C.; Lee, J. W.; Nordblom, G. D.; Das, I.; DeSilva, B. S.; Khan, M. N.; Bowsher, R. R.; J. Pharm. Biomed. Anal. 2000, 21, 1249 .

14. Hammock, B. D.; Mumma, R. O. Em Recent advances in pesticide analytical methodology; Harvey, J.; Zweig, Z., eds.; American Chemical Society: Washington, DC, 1980, p. 321.

15. US EPA; Test methods for evaluation of solid and aqueous waste: physical/ chemical methods, $3^{\text {rd }}$ ed., US EPA: Washington, DC, 1996.

16. Wie, S. I.; Hammock, B. D.; J. Agric. Food Chem. 1992, 30, 949.

17. Behnisch, P. A.; Hosoe, K.; Sakai, S.-I.; Environ. Int. 2001, 27, 413.

18. Krämer, P. M.; Marco, M. P.; Hammock, B. D.; J. Agric. Food Chem. 1994, 42, 934.

19. Yau, K. Y. F. ; Lee, H.; Hall, C. J.; Biotechnol. Adv. 2003, 21, 599.

20. Spinks, C. A.; Trends Food Sci. Technol. 2000, 11, 210.

21. Schneider, P.; Goodrow, M. H.; Gee, S. J.; Hammock, B. D.; J. Agric. Food Chem. 1990, 42, 413.

22. Meulenberg, E. P.; Mulder, W. H.; Stoks, P. G.; Environ. Sci. Technol. 1995, 29, 553.

23. Benjamini, I. E.; Leskowitz, S.; Immunology: a short course, $2^{\text {nd }}$ ed., WileyLiss: New York, 1991.

24. Harrison, R. O.; Goodrow, M. H.; Gee, S. J.; Hammock, B. D. Em Immunoassay for trace chemical analysis; Vanderlaan, M.; Stanker, L.; Watkins, B.; Roberts, D., eds.; American Chemical Society: Washington, DC, 1990

25. Goodrow, L. W.; Sanborn, J. R.; Stoutamire, D. W.; Gee, S. J.; Hammock, B. D. Em Immunoanalysis of agrochemicals; Nelson, J. O.; Karu, A. E.; Wong, R. B., eds.; American Chemical Society: Washington, DC, 1995.

26. Marco, M. P.; Gee, S. J.; Hammock, B. D.; Trends Anal. Chem. 1995, 14, 415 .

27. Sherry, J. P.; Crit. Rev. Anal. Chem. 1992, 23, 217.

28. Erlanger, B. F.; Methods Enzymol. 1980, 70, 85.

29. Tijssen, P.; Practice and theory of enzyme immunoassays, Elsevier: Amsterdam, 1985.

30. Bauminger, S.; Wilcheck, M.; Methods Enzymol. 1980, 70, 151.

31. Burrin, J.; Newman, D. J. Em Principles and practice of immunoassay; Price, C. P.; Newman, D. J., eds.; Stockton Press: New York, 1991, p. 19.

32. Wortberg, M.; Cammann, K.; Strupat, K.; Hillenkamp, K.; Fresenius J. Anal. Chem. 1994, 348, 240.

33. Wong, S. S.; Chemistry of protein conjugation and cross-linking, CRC Press, Inc.: Boca Raton, Florida, 1993.

34. Kamps-Holtzapple, C.; Carlin, R. J.; Sheffield, C.; Kubena, L.; Stanker, L.; Deloach, J. R.; J. Immunol. Methods 1993, 164, 245.

35. Pichon, V.; Chen, L.; Hennion, M. C.; Daniel, R.; Martel, A.; Le Goffic, F.; Abian, J.; Barceló, D.; Anal. Chem. 1995, 67, 2451.

36. Szurdoki, F.; Bekheit, H. K.; Marco, M. P.; Goodrow, M. H.; Hammock, B. D. Em New frontiers in agrochemical immunoassays; Kurtz, D. A.; Skerrit, J. H.; Stanker, L., eds.; AOAC International: Arlington, VA, 1995.

37. Siegel, M. M.; Tsuo, H. R.; Lin, B. W.; Hollander, I. J.; Wissner, A.; Karas, M.; Ingendoh, A.; Hillenkamp, F.; Biol. Mass Spectrom. 1993, 22, 369.

38. Straub, K. M.; Levy, M. J.; Bioconj. Chem. 1994, 5, 194.
39. Hurn, B. A. L.; Chantler, S. M.; Methods Enzymol. 1980, 70, 104.

40. Dresser, D. W. Em Handbook of experimental immunology. Immunochemistry; Weir, D. M., ed.; Blackwell Scientific Publications: Oxford, 1986

41. Churchill, R. L. T.; Sheedy, C.; Yau, K. Y. F.; Hall, J. C.; Anal. Chim. Acta 2002, 468, 185 .

42. Hendrickson, O. D.; Zherdev, A. V.; Kaplun, A. P.; Dzantiev, B. B.; Mol. Immunol. 2002, 39, 413.

43. Roitt, I.; Essential immunology, Blackwell Scientific Publications: Oxford, 1980.

44. O'Shaughnessy, D. J. Em Radioimmunoassay of gut regulatory peptide; Bloom, R. S.; Long, R. G., eds.; W. B. Saunders: London, 1982, p. 11.

45. Bomford, R. Em Adjuvants in animal cell biotechnology; Spier, R.; Griffiths, B., eds.; Academic Press: New York, 1985, p. 235.

46. Allison, A. C.; Byars, N. E.; J. Immunol. 1986, 95, 157.

47. Gregoriadis, G.; Immunol. Today 1990, 11, 89.

48. Gosling, J. P.; Immunoassay, Academic Press, Inc.: New York, 1996, p. 283.

49. Vaitukaits, J. L.; Robbins, J. B.; Nieschlag, E.; Ross, G. T.; J. Clin. Endocrinol. Metab. 1971, 33, 988.

50. Corrie, J. E. T. Em Immunoassays for clinical chemistry; Hunter, W. M.; Corrie, J. E. T., eds.; Churchill Livingstone: Edinburgh, 1983, p. 469.

51. Bienenstock, J.; Befus, A. D.; Immunol. 1980, 41, 249.

52. Schur, P.; Prop. Clin. Immunol. 1972, 1, 71.

53. Kaushik, A.; Shojaei, F.; Saini, S. S.; Vet. Immunol. Immunophatol. 2002 87, 347.

54. Bruggemann, M.; Neuberger, M. S.; Imunol Today 1996, 17, 391.

55. Tout, N. L.; Yau, K. Y. F.; Trevors, J. T. ; Lee, H.; Hall, J. C.; J. Agric. Food. Chem. 2001, 49, 3628.

56. Rader, C.; Ritter, G.; Nathan, S.; Elia, M.; Gout, I.; Junghbluth, A. A.; $J$. Biol. Chem. 2000, 275, 13668.

57. Saini, S. S.; Hein, W. R.; Kaushik, A.; Mol. Immunol. 1997, 34, 641.

58. O'Brien, P. M.; Aitken, R.; O'Neil, B. W.; Campo, M. S.; Proc. Natl. Acad. Sci. U.S.A. 1999, 96, 640.

59. Muyldermans, S.; Rev. Mol. Biotechnol. 2001, 74, 277.

60. Tanha, J.; Xu, P.; Chen, Z.; Ni, F.; Kaplan, H.; Narang, S. A.; J. Biol. Chem. 2001, 276, 24774

61. Klein, J.; Proc. Natl. Acad. Sci. U.S.A. 1998, 95, 11504.

62. Hsu, E.; Immunol. Rev. 1998, 162, 25.

63. Andris-Widhopf, J.; Rader, C.; Steinberger, .P; Fuller, R.; Barbas III, C. F.; J. Immunol. Methods 2000, 242, 159.

64. Hedlund, G. P.; Hau, J.; In Vivo 2001, 15, 381

65. Manson, M. M., ed.; Immunochemical protocols, Humana Press: Totowa, New Jersey, 1992, p. 480.

66. Gil, E. S.; Kubota, L. T.; Yamamoto, Y. I.; Quim. Nova 1999, 22, 874.

67. Köhler, G.; Milstein, C.; Nature 1975, 256, 495.

68. Hudson, P. J.; Souriau, C.; Expert Opin. Biol. Ther. 2001, 1, 845.

69. Lamari, F.; Anastassiou, E. D.; Dimitracopoulus, G.; Karamanos, N. K.; J. Pharm. Biomed. Anal. 2000, 23, 939.

70. Hammock, B. D.; Gee, S. J.; Harrison, R. O.; Jung, F.; Goodrow, M. H.; Li, Q. X.; Lucas, A. D.; Szecaks, A.; Sundaram, S. Em Immunochemical methods for environmental analysis; Vanderlaan, M.; Stanker, L. H.; Watkins, B. E.; Roberts, D. W., eds.; American Chemical Society: Washington, DC, 1990, p. 112.

71. Niessner, R.; Anal. Met. Instrum. 1993, 1, 134

72. Mukerjee, S.; McKnight, M.E.; Glassy, M. C.; Expert Opin. Invest. Drugs 1998, 7, 361 .

73. Schwalbe, M.; Dorn, E.; Beyermann, K.; J. Agric. Food Chem. 1984, 32 , 734

74. Hawcroft, D.; Hector, T. Em Quantitative Bioassay. Analytical Chemistry by Open Learning; Rowell, F., ed.; John Wiley \& Sons: London, UK, 1987, p. 65 .

75. Miles, L. E.; Hayes, C. N.; Nature 1968, 219, 188.

76. Van Weeman, B. K.; Schuurs, A. H.; FEBS Lett. 1974, 43, 215.

77. Johannsson, A. Em Principles and practice of immunoassay; Price, C. P.; Newman, D. J., eds.; Stockton Press: New York, 1991, p. 295.

78. Catt, K.; Tregear, C. W.; Science 1967, 158, 1570.

79. Chapman, R. S.; Sutherland, R. M.; Ratcliffe, J. G. Em ref. 50, p. 178

80. Kemeny, D. M.; Challacombe, S. J. Em ELISA and other solid phase immunoassays: theoretical and practical aspects; Kemeny, D. M.; Challacombe, S. J., eds.; John Wiley and Sons: Chichester, 1988, p. 31.

81. Hennion, M. C.; Barceló, D.; Anal. Chim. Acta 1998, 36, 3.

82. Price, C. P.; Newman, D. J. Em ref. 77, p. 78.

83. Clark, P. M. S.; Price, C. P.; Clin. Chem. 1986, 32, 88.

84. Montoya, A. A.; Anal. Chim. Acta 1995, 311, 365.

85. Nunes, G. S.; Marco, M-P.; Barceló, D.; Ribeiro, M. L.; J. Chromatogr., A 1998, 823, 109 .

86. Nunes, G. S.; Barceló, D.; Trends Anal. Chem. 1999, 18, 99. 
87. Nunes, G. S.; Toscano, I. A.; Ribeiro, M. L.; Barceló, D.; Quim. Nova 2000 $23,466$.

88. Gee, S. J.; Hammock, B. D.; Van Emon, J. M.; A guide to environmental immunochemical analysis, EPA/540/R-94/509, March, 1994.

89. Hottenstein, C. S.; Jourdan, S. W.; Hayes, M. C.; Rubio, F. M; Herzog, D. P.; Lawruk, T. M.; Environ. Sci. Technol. 1995, 29, 2754.

90. Rodbard, D. Em Ligand assay: analysis of international developments of isotopic and nonisotopic immunoassay; Langan, J.; Clapp, J. J., eds.; Masson Publishing USA Inc.: New York, 1981, p. 45.

91. Barceló, D.; Hennion, M. C., eds. Em Techniques and instrumentation in analytical chemistry, Elsevier: Amsterdam, 1997.

92. Nordling, M.; Haglung, P.; Anal. Chim. Acta, 2003, 487, 43.

93. Székács, A.; Le, H. M.; Knopp, D.; Niessner, R.; Anal. Chim. Acta 1999, 399, 127.

94. Nunes, G. S.; Barceló, D. Em Encyclopedia of Separation Science; Edição 2000 , p. 21, 91, 2201

95. Hall, J. C.; Deschamps, R. J. A.; Krieg, K. K.; J. Agric. Food Chem. 1989, $37,981$.

96. Krämer, K.; Lepschy, J.; Hock, B.; J. Assoc. Off. Anal. Chem. 2001, 84, 150.

97. Jaeger, L. L.; Jones, A. D.; Hammock, B. D.; Chem. Res. Technol. 1998, 11,342 .

98. Clegg, B. B.; Stephenson, G. R.; Hall, J. C.; J. Agric. Food Chem. 2001 49, 2168.

99. Clegg, B. B.; Stephenson, G. R.; Hall, J. C.; J. Agric. Food Chem. 1999 47, 5031 .

100. Casino, P.; Morais, S.; Puchades, R.; Maquieira, A.; Environ. Sci. Technol 2001, 35, 4111 .

101. Spinks, C. A.; Wang, B.; Mills, E. N. C.; Morgan, M. R. A.; Analyst 1999, $124,847$.

102. Deschamps, R. J. A.; Hall, J. C. Em ref. 70, p. 66

103. Miyake, S.; Hayashi, A.; Kumeta, T.; Kitajima, K.; Kita, H.; Ohkawa, H.; Biosci. Biotechnol. Biochem. 1998, 62, 1001.

104. Watanabe, E.; Kanzaki, Y.; Tokumoto, H.; Hoshino, R.; Kubo, H.; Nakazawa, H.; J. Agric. Food Chem. 2002, 50, 53

105. Szurdoki, S.; Szécáks, A.; Le, H. M.; Hammock, B. D.; J. Agric. Food Chem. 2002, 50, 29.

106. Alcocer, M. J.; Doyen, C.; Lee, H. A.; Morgan, M. R.; J. Agric. Food Chem. 2000, 48, 335 .

107. Schmidt, P.; Kuhlmman, R.; Losch, U.; Z. Naturforsch. 1988, 43, 167.

108. Shan, G.; Wang, W.; Gee, S.J.; Buchholz, B. A.; Vogel, J. S.; Hammock, B. D.; Proc. Natl. Acad. Sci. U.S.A. 2000, 97, 24.

109. Bushway, R. J.; Young, B. E.; Paradis, L. R.; Perkins, L. B.; J. Assoc. Off. Anal. Chem. Int. 1994, 77, 1243.

110. Gueguen, F.; Boisde, F.; Queffelec, A. L.; Haelters, J. P.; Thouvenot, D. Corbel, B.; J. Agric. Food Chem. 2000, 48, 4492.

111. Tanaka, T.; Ikebushi, H.; Sawada, J. I.; Okada, M.; Kido, Y.; J. Assoc. Off. Anal. Chem. Int. 1996, 79, 426.

112. Noguera, P.; Maquieira, A.; Puchades, R.; Brunet, E.; J. Environ. Monit. 2002, 4, 442

113. Marco, M. P.; Nasiri, M.; Kurth, M. J.; Hammock, B. D.; Chem. Res. Technol. 1993, 6, 284.

114. De Meulenaer, B.; Baert, K.; Lanckriet, H.; Van Hoed, V.; Huyghebaert, A.; J. Agric. Food Chem. 2002, 50, 5273.

115. Fritcher, D. L.; Mazet, J. A. K.; Ziccardi, M. H.; Gardner, I. A.; Mar. Pollut Bull. 2002, 44, 388.

116. Kim, I. S.; Ritchie, L.; Setford, S.; Taylor, J.; Allen, M.; Wilson, G.; Heywood, R.; Pahlavanpour, B.; Saini, S.; Anal. Chim. Acta 2001, 450, 13.

117. Jonhson, J. C.; Van Emon, J. M.; Clarke, A. N.; Wamsley, B. N.; Anal Chim. Acta 2001, 428, 191.

118. Gerdes, M.; Meusel, M.; Spener, F.; Anal. Biochem. 1997, 252, 198.

119. Choi, M. J.; Jo, C.; Choi, J.; Kang, C.-Y.; Han, C. T.; J. Immunoassay Immunochem. 1999, 20, 57.

120. Skládal, P.; Biosens. Bioelectron. 1999, 14, 63.

121. Liegeois, E.; Dehon, Y.; De Brabant, B.; Perry, P.; Portetelle, D.; Copin, A.; Sci. Total Environ. 1992, 123, 17.

122. Nagao, M.; Takatori, T.; Wu, B.; Tarazawa, K.; Gotoudam H.; Akabane, H.; J. Immunoassay Immunochem. 1989, 10, 1.

123. Holthues, H.; Pfeifer-Fukumura, U.; Hartmman, I.; Baumann, W.; Fresenius' J. Anal. Chem. 2001, 371, 897.

124. Mercader, J. V.; Montoya, A.; J. Agric. Food Chem. 1999, 47, 1276

125. Moreno, M. J.; Abad, A.; Montoya, A.; J. Agric. Food Chem. 2001, 49, 72
126. Abad, A.; Moreno, M. J.; Pelegri, R.; Martinez, M. I.; Saez, A.; Gamon, M.; Montoya, A.; J. Agric. Food Chem. 2001, 49, 1707.

127. Abad, A.; Moreno, M. J.; Pelegri, R.; Martinez, M. I.; Saez, A.; Gamon, M.; Montoya, A.; J. Chromatogr., A 1999, 833, 3.

128. Haasnoot, W.; Stouten, P.; Cazemier, H.; Lommen, A.; Nouws, J. F. M.; Keukens, H. J.; Analyst 1999, 124, 301.

129. Kolosova, A. Y.; Blintsov, A. N.; Samsonova, J. V.; Egorov, A. M.; Fresenius' J. Anal. Chem. 1998, 361, 329.

130. Schnappinger, P.; Uselber, E.; Martlbauer, E.; Terplan, G.; Food Agric. Immunol. 1993, 124, 301.

131. Heering, W.; Usleber, E.; Dietrich, R.; Marltlbauer, E.; Analyst 1998, 123, 2759.

132. Hammer, P.; Kirchhoff, H.; Hahn, G.; Anal. Chim. Acta 1993, 275, 313.

133. Leickt, L.; Grubb, A.; Ohlson, S.; J. Immunol. Methods 1998, $220,19$.

134. Li, Y.; Cockburn, W.; Kilpatrick, J.; Whitelam, G. C.; Food Agric. Immunol. 1999, 11,5 .

135. Li, K.; Woodward, L. A.; Karu, A. E.; Li, Q. X.; Anal. Chim. Acta 2000, $419,1$.

136. Soh, N.; Tokuda, T.; Watanabe, T.; Mishima, K.; Imato, T.; Masadome, T.; Asano, Y.; Okutani, S.; Niwa, O.; Brown, S.; Talanta 2003, 60, 733

137. Roy, S.; Mysior, P.; Brzezinski, R.; Chemosphere 2002, 48, 833.

138. Ahmed, F. E.; Trends Anal. Chem. 2003, 22, 170.

139. Harrison, R. O.; Eduljee, G. H.; Sci. Total Environ. 1999, $239,1$.

140. Behnisch, P.A.; Hosoe, K.; Sakai, S.; Environ. Int. 2001, 27, 413.

141. Behnisch, P.A.; Hosoe, K.; Sakai, S.; Environ. Int. 2001, 27, 495.

142. Díaz-Ferrero, J.; Rodríguez-Larena, M. C.; Comellas, L.; Jiménez, B.; Trends Anal. Chem. 1997, 16, 563.

143. Hawkins, P. R.; Chandrasena, N. R.; Jones, G. J.; Falconer, I. R.; Toxicon 1997, 35, 341

144. Jochimsen, E. M.; Carmichael, W. W.; An, J. S.; Cardo, D. M. ; Cookson, S. T.; New Engl. J. Med. 1998, 338, 873.

145. Magalhães, V. F.; Marinho, M. M.; Domingos, P.; Oliveira, A. C.; Costa, S. M.; Azevedo, L. O.; Azevedo, S. M. F. O.; Toxicon 2003, 42, 289.

146. Zeck, A.; Eikenberg, A.; Weller, M. G.; Niessner, R.; Anal. Chim. Acta 2001, 441, 1 .

147. Mehto, P.; Ankelo, M.; Hinkkanen, A.; Mikhailov, A.; Eriksson, J. E.; Spoof, L.; Meriluoto, J.; Toxicon 2001, 39, 831.

148. McElhiney, J.; Lawton, L. A.; Porter, A. J. R.; FEMS Microbiol. Lett. 2000, $193,83$.

149. Metcalf, J. S.; Beattie, K. A.; Pflugmacher, S.; Codd, G. A.; FEMS Microbiol. Lett. 2000, 189, 155.

150. Metcalf, J. S.; Bell, S. G.; Codd, G. A.; Water Res. 2000, 34, 2761

151. McDermott, C. M.; Feola, R.; Plude, J.; Toxicon 1995, 33, 1433.

152. Shah, V. P. ; Midha, K. K.; Pharm. Res. 1992, 9, 588.

153. Findlay, J. W. A.; Smith, W. C.; Lee, J. W.; Nordblom, G. D.; Das, I.; DeSilva, B. S. J.; Khan, M. N.; Bowsher, R. R.; J. Pharm. Biomed. Anal. 2000, 21, 1249.

154. Miller, K. A.; Addison, R. F.; Bandiera, S. M.; Mar. Environ. Res. 2003, 57, 37.

155. Schoket, B.; Papp, G.; Lévay, K.; Mracková, G..; Kadlubar, F. F.; Vinkze, I.; Mutat. Res. 2001, 482, 57.

156. Boysen, G.; Hecht, S. S.; Mutat. Res. 2003, 543, 17.

157. Lambert, P. ; Fingas, M.; Groldthorp, M.; J. Hazard. Mater. 2001, 83, 65.

158. Kriek, E.; Rojas, M.; Alexandrov, K.; Bartsch, H.; Mutat. Res. 1998, 400, 215.

159. Schoket, B.; Poirier, M. C.; Mayer, G.; Török, G.; Kolozki-Ringelhann, A.; Bognár, G.; Bigbee, W. L.; Vinkze, I.; Mutat. Res. 1999, 445, 193.

160. Krämer, P.; Anal. Chim. Acta 1998, 376, 3.

161. Knopp, D.; Anal. Chim. Acta 1995, 311, 383.

162. Gabaldón, J. A.; Maquieira, A.; Puchades, R.; Crit. Rev. Food Sci. Nut. 1999, 39, 519.

163. Fernandez-Alba, A. R.; Valverde, A.; Agüera, A.; Contreras, M.; Rodriguez, D.; Anal. Chim. Acta 1995, 311, 371

164. Beasley, H. L.; Skerritt, J. H.; Hill, A. S.; Desmarchelier, J. M.; J. Stor. Prod. Res. 1993, 29, 357

165. Riccardi, C. S.; Costa, P. I.; Yamanaka, H.; Quim. Nova 2002, 25, 316.

166. Freire, R. S.; Pessoa, C. A.; Mello, L. D.; Kubota, L. T.; J. Braz. Chem. Soc. 2003, 14, 230

167. Nunes, G. S.; Toscano, I. A.; Barceló, D.; Trends Anal. Chem. 1998, 17, 79.

168. Chiang, J. C.; Van Emon, J. M.; Chou, Y-L.; Junod, N.; Finegold, J. K.; Wilson, N. K.; Anal. Chim. Acta 2003, 486, 31

169. Paek, S-H.; Lee, S-H.; Cho, J-H.; Kim, Y-S.; Methods 2000, 22, 53.

170. Nilsson, S.; Layer, C.; Laurell, T.; Birnbaum, S.; Anal. Chem. 1995, 67, 3051 . 